\title{
Targeting European Respiratory Society group activities: a survey of the Noninvasive Ventilatory Support Group
}

\author{
To the Editor:
}

According to the European Respiratory Society (ERS) philosophy, the Assemblies and their Groups are the "beating heart" of the Society so that "joining one and participating in its activities are among the most significant benefits of membership" [1]. Likewise, one of the missions of the ERS Assembly activities is to gather all cultural stimuli from its members with the aim of producing scientific data, educational materials, and new ideas to improve research and its translation into clinical practice in different environments worldwide. In other words, the ERS Groups (should) act as a "catalyst" of different minds, working together to increase communication among each other.

Moreover, the ERS Groups also intend to build-up active strategies, thus attracting the interests of new members through the dissemination of exciting activities. This is particularly true when the Group is built on the interest of a "transverse" technique, such as noninvasive ventilation (NIV) [2]. NIV has re-written the history of mechanical ventilation and, most importantly, is handled by different specialists (pulmonologists, intensivists, emergency medical doctors, neurologists, cardiologists, etc.) and different professional figures (medical doctors, nurses, physiotherapists and technicians) using different tools (machines, circuits and interfaces) in different clinical scenarios (acute, chronic and acute-on-chronic respiratory failure). Furthermore, physicians dealing with different fields of respiratory medicine (e.g. infective diseases, diffuse lung diseases, chronic obstructive diseases, interventional pulmonology, paediatrics, oncology and palliative care) may be interested in the "NIV world" due to its huge, and still increasing, field of diagnostic and therapeutic applications.

On behalf of the Respiratory Intensive Care Assembly, we recently conducted a survey about the interests, professional attitude and characteristics of the members of the Noninvasive Ventilatory Support Group. The specific aims of this survey were to: improve the "link" between the large number of members and the programme activity of the Group; and increase the visibility of the Group activities for clinicians associated with the other ERS Groups.

Of the 377 members, the response rate was 46\% (table 1). Most of the respondents were Europeans of young to middle age working as medical doctors in pulmonary departments with or without a respiratory intensive care unit (RICU). This was not surprising as NIV is a typical "landmark" of different levels of RICUs [3]. In terms of intensity of nursing care provided, the majority of them belonged to an ordinary ward. Again, this finding is in line with published data corroborating the possibility of using NIV in an ordinary ward to manage less severely ill acute patients, as well as to care for the adaptation to domiciliary NIV $[4,5]$. The choice of the setting for acute application of NIV is dependent on the type and severity of acute respiratory failure (ARF), the expertise of the staff, and the intensity of care and monitoring provided [4]. The heterogeneity of the environment where the surveyed members work is not unexpected given the key relevance of NIV in different clinical areas [2]. This also reflects the timing of the "usual" applications of this ventilator technique (i.e. prevention of impending ARF, avoidance of endotracheal intubation, and an alternative to invasive mechanical ventilation) [6], as well as the so-called "unusual indications" of NIV (e.g. cardiopulmonary interventional procedures, post-operative ARF, chest trauma and palliative care) [7].

The number of departments with at least five medical professionals who were familiar enough with NIV to be able to autonomously perform this support at any time for ARF was 59\% for nurses, 56\% for medical doctors and $18 \%$ for physiotherapists. This finding is not surprising as, at least within Europe, NIV is largely performed by nurses [8]. More specifically, the members stated to have been able to perform NIV without supervision in only $30 \%$ and $36 \%$ of patients receiving ventilation for acute and chronic respiratory failure, respectively. This data highlights the crucial role of team training for successful NIV application in ARF according to the "learning curve" needed to acquire adequate experience [9]. Thus, the activities of the Noninvasive Ventilatory Support Group and the Respiratory Intensive Care Assembly have focused on educational aims by promoting: ERS Postgraduate courses; the respiratory critical care medicine HERMES (Harmonising Education in Respiratory Medicine for European Specialists) syllabus [10]; Task Forces (e.g. RICU 
TABLE 1 Respiratory Intensive Care Assembly survey

Survey items

Response \%

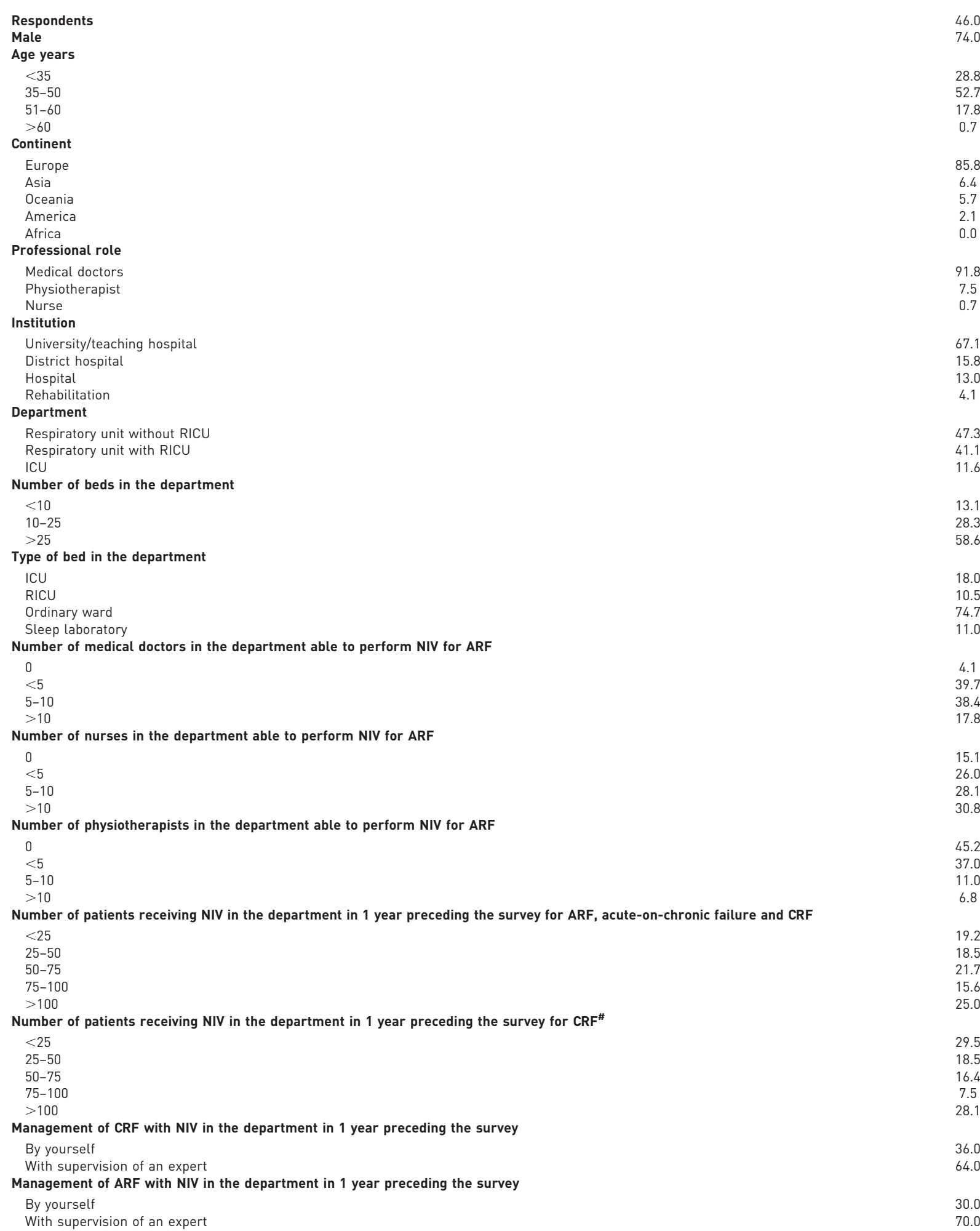

RICU: respiratory intensive care unit; ICU: intensive care unit; NIV: noninvasive ventilation; ARF: acute respiratory failure; CRF: chronic respiratory failure. ${ }^{\#}$ : both newly initiated and monitored on long-term NIV. 
features and ethical issues in RICU) [3, 11]; fellowships; and the Junior Members Committee within the Long Range Planning Committee.

In conclusion, the findings of our survey depict the characteristics of the Noninvasive Ventilatory Support Group members as a heterogeneous pool of subjects, showing a different degree of expertise with a predominance of pulmonologists who manage patients in low-intensity settings with both acute and chronic respiratory failure. Current and future activities of the Group and its Assembly are directed to increase the awareness of all ERS members to the central role covered by NIV in respiratory medicine and to coherently improve the skills of old and new members.

@ERSpublications

Survey showing ERS NIV group is heterogeneous with different degree of expertise and predominance of pulmonologists http://ow.ly/tAa0D

Raffaele Scala ${ }^{1}$, Wolfram Windisch ${ }^{2}$, Thomas Köhnlein ${ }^{3}$, Antoine Cuvelier ${ }^{4,5}$, Paolo Navalesi ${ }^{6,7,8}$ and Paolo Pelosi ${ }^{9}$ on behalf of European Respiratory Society Respiratory Intensive Care Assembly

${ }^{1}$ Pulmonology Unit and Respiratory Intensive Care Unit, S. Donato Hospital, Arezzo, Italy. ${ }^{2}$ Dept of Pneumology, Cologne-Merheim Hospital, Cologne, Germany. ${ }^{3}$ Dept of Respiratory Medicine, Hannover Medical School, Hannover, Germany. ${ }^{4}$ Pulmonary and Intensive Care Dept, Rouen University Hospital, Rouen, France. ${ }^{5}$ UPRES EA 3830 (IFR MP23), Institute for Biomedical Research, Rouen, France. ${ }^{6}$ Dept of Translational Medicine, Università del Piemonte Orientale "Amedeo Avogadro", Novara, Italy. ${ }^{7}$ Anaesthesia and Intensive Care Medicine, Sant'Andrea Hospital (ASL VC), Vercelli, Italy. ${ }^{8}$ CRRF Mons. L. Novarese, Moncrivello, Italy. ${ }^{9}$ Dept of Surgical Sciences and Integrated Diagnostics, University of Genoa, Genoa, Italy.

Correspondence: Raffaele Scala, Pulmonology Unit and Respiratory Intensive Care Unit, S. Donato Hospital, Via P. Nenni, 20, Arezzo, Italy. E-mail: raffaele_scala@hotmail.com

Received: Sept 212013 | Accepted after revision: Oct 092013

Conflict of interest: Disclosures can be found alongside the online version of this article at err.ersjournals.com

Provenance: Submitted article, peer reviewed.

\section{References}

European Respiratory Society. Who we are. www.ersnet.org/about-us/who-we-are.html Date last accessed: September 1, 2013.

Nava S, Hill N. Non-invasive ventilation in acute respiratory failure. Lancet 2009; 374: 250-259.

Corrado A, Roussos C, Ambrosino N, et al. Respiratory intermediate care units: a European survey. Eur Respir J 2002; 20: 1343-1350.

Hill NS. Where should noninvasive ventilation be delivered? Respir Care 2009; 54: 62-70.

Ozsancak A, D’Ambrosio C, Hill NS. Nocturnal noninvasive ventilation. Chest 2008; 133: 1275-1286.

Nava S, Navalesi P, Conti G. Time of non-invasive ventilation. Intensive Care Med 2006; 32: 361-370.

Ambrosino N, Guarracino F. Unusual applications of noninvasive ventilation. Eur Respir J 2011; 38: 440-449.

Nava S, Evangelisti I, Rampulla C, et al. Human and financial costs of noninvasive mechanical ventilation in patients affected by COPD and acute respiratory failure. Chest 1997; 111: 1631-1638.

9 Carlucci A, Delmastro M, Rubini F, et al. Changes in the practice of non-invasive ventilation in treating COPD patients over 8 years. Intensive Care Med 2003; 29: 419-425.

10 Artigas A, Pelosi P, Dellweg D, et al. Respiratory critical care HERMES syllabus: defining competencies for respiratory doctors. Eur Respir J 2012; 39: 1294-1297.

11 Nava S, Sturani C, Hartl S, et al. End-of-life decision-making in respiratory intermediate care units: a European survey. Eur Respir J 2007; 30: 156-164.

\section{Chronic thromboembolic pulmonary hypertension complicating long-term cyproterone acetate therapy}

To the Editor:

Chronic thromboembolic pulmonary hypertension (CTEPH) is the most severe delayed complication after pulmonary embolism. Known risk factors of CTEPH include acute pulmonary embolism, the degree of 